ORIGINAL ARTICLE

\title{
Akt activation and localisation correlate with tumour invasion and oncogene expression in thyroid cancer
}

\author{
V Vasko, M Saii, E Hardy, M Kruhlak, A Larin, V Savchenko, M Miyakawa, O Isozaki, \\ H Murakami, T Tsushima, K D Burman, C De Micco, M D Ringel
}

J Med Genet 2004;41:161-170. doi: 10.1136/jmg.2003.015339

See end of article for authors' affiliations

Correspondence to:

Dr M D Ringel, Associate

Professor of Medicine,

Divisions of Endocrinology

and Oncology, 455D

McCambell Háll, 1581

Dodd Drive, Columbus,

$\mathrm{OH}$ 43210, USA;

ringel-1@medctr.osu.edu

Received 9 October 2003

Accepted 9 October 2003
Introduction: Akt activation is involved in the pathogenesis of inherited thyroid cancer in Cowden's syndrome and in sporadic thyroid cancers. In cell culture, Akt regulates thyroid cell growth and survival; but recent data suggest that Akt also regulates cell motility in non-thyroid cell lines. We therefore sought to evaluate the role of Akt in thyroid cancer progression.

Methods: We evaluated 46 thyroid cancer, 20 thyroid follicular adenoma, and adjacent normal tissues samples by immunohistochemistry for activated Akt (pAkt), Akt 1, 2, and 3, and p27 expression. Immunoblots were performed in 14 samples.

Results: Akt activation was identified in 10/10 follicular cancers, $26 / 26$ papillary cancers, and 2/10 follicular variant of papillary cancers, but in only 4/66 normal tissue samples and 2/10 typical benign follicular adenomas. Immunoactive pAkt was greatest in regions of capsular invasion; and was localised to the nucleus in follicular cancers and the cytoplasm in papillary cancers, except for invasive regions of papillary cancers where it localised to both compartments. Immunoactive Akt 1, but not Akt 2 or Akt 3, correlated with pAkt localisation, and nuclear pAkt was associated with cytoplasmic expression of p27. In vitro studies using human thyroid cancer cells demonstrated that nuclear translocation of Akt 1 and pAkt were associated with cytoplasmic p27 and cell invasion and migration. Cell migration and the localisation of Akt 1, pAkt, and p27 were inhibited by PI3 kinase, but not MEK inhibition.

Discussion: These data suggest an important role for nuclear activation of Akt 1 in thyroid cancer progression.
$\mathrm{T}$ hyroid cancer is a heterogeneous disorder characterised by gene mutations that activate signalling pathways, and also by abnormalities in tumour suppressor genes and cell cycle proteins. ${ }^{1}$ The development of local invasion outside the thyroid capsule and of distant metastases predicts a poor response to radioiodine therapy and subsequent progression and mortality from thyroid cancer. ${ }^{23}$ Because there are no effective alternative therapies for patients with metastatic thyroid cancer that does not respond to iodine, there is a need to better understand the pathways responsible for aggressive thyroid cancer cell growth and progression in order to determine appropriate therapeutic targets.

Activation of the Akt/PKB signaling pathway appears to play an important role in thyroid tumorigenesis. Of significance for thyroid cancer, Akt is activated in Cowden's syndrome, an autosomal dominant multiorgan hamartoma syndrome characterised by benign and malignant thyroid tumours, breast cancers, and colon cancers. ${ }^{45}$ In addition, Akt activation, probably through a variety of mechanisms, also occurs in the majority of sporadic thyroid cancers. ${ }^{6}$ In benign thyroid cell models, Akt signalling is important for thyroid cell growth in response to insulin, insulin-like growth factor-1 (IGF-1), and serum, ${ }^{7-10}$ and is activated by several common thyroid cancer oncogenes, including activated $\mathrm{p} 2 \mathrm{I}^{\text {ras }}$ and chimeric rearrangements involving the ret gene (RET/PTC oncogenes). ${ }^{11-22}$ Despite these data implicating a central role for Akt activation in thyroid tumorigeneis, little is known about the role Akt may play in the progression of either inherited or sporadic thyroid carcinoma.

Akt (protein kinase B; PKB, RAC), represents a family of proteins that was initially cloned as a homologue to the AKT8 viral oncogene. ${ }^{23-25}$ All Akt isoforms (Akt 1, 2, and 3 will be referred to as Akt) share structural similarity to protein kinases $\mathrm{A}$ and $\mathrm{C}$ and contain a pleckstrin homology domain, making it a target for phospholipids produced by PI3 kinase activity. Akt activation involves non-receptor initiated phosphorylation at Thr450, cytoplasmic membrane insertion, and phosphorylation at Thr308 and Ser473 for Akt 1 and at homologous sites for Akt 2 and 3. ${ }^{26-28}$ Phosphorylation of Thr308 is mediated by phosphoinositide dependent kinase 1 , but the mechanisms that regulate ser473 phosphorylation remain controversial. The expression patterns of the three Akt isoforms differ, as do their apparent biological activities. ${ }^{24}{ }^{29-36}$ Akt2 appears to be expressed at greater levels in insulin responsive tissues. ${ }^{33}$ Consistent with these data, Akt2 knockout mice develop mild type 2 diabetes, ${ }^{37}$ while Aktl knockout mice are non-diabetic, but small in size. ${ }^{38}$ Akt3 expression is more limited, occurring in brain, heart, kidney, and in some poorly differentiated cancers. ${ }^{32}$

Once activated, Akt then binds to several chaperone proteins, including heat shock protein $90,{ }^{39}$ APPL ${ }^{40}$ PRK2, ${ }^{41}$ CTMP, ${ }^{42}$ and TCL1. ${ }^{43-45}$ Some of these carrier proteins demonstrate Akt isoform specificity, particularly APPL for Akt $2^{40}$ and TCLl for Akt $\mathrm{l}$ and Akt 3. ${ }^{46}$ Downstream effectors of Akt are involved in metabolic, anti-apoptotic, growth stimulatory, and motility related pathways. At a consensus recognition sequence, Akt directly phosphorylates and modifies the function of forkhead transcription factors FKHRL1, FHHl, and AFX, IKK $\alpha$, caspase 9, telomerase, mTOR, PHAS1, glycogen synthesis kinase 3 (GSK3), BAD,

Abbreviations: AA, atypical adenoma; FA, follicular adenoma; FC, follicular carcinoma; FVPC, follicular variant of papillary carcinomas; IGF, insulin-like growth factor; MMP, matrix metalloproteinase; PC, papillary carcinomas 
and others. ${ }^{47-50}$ The majority of these targets are located in the cytosol, but some appear to be primarily phosphorylated by Akt in the nucleus (reviewed by Nicholson and Anderson ${ }^{48}$ ), suggesting that compartmentalisation of activated Akt may be important in determining its cellular effects.

A functional role for Akt in cell motility was first reported by Meili et al, ${ }^{51}$ who demonstrated the requirement of activation and cytoplasmic membrane localisation of Akt for efficient cyclic AMP activated chemotaxis in Dictyostelium. Servant $e t a l^{52}$ subsequently demonstrated similar effects in neutrophils, suggesting a broad role for Akt activation in cell motility. In cancer cell models, IGF-l and EGF mediated extracellular matrix invasion was demonstrated to be PI3 kinase and Akt dependent in pancreatic and breast cancer models, respectively ${ }^{53}$ Akt has also been shown to localise to the sites of epithelial matrix contact suggesting a role in cell-environment interactions.

These indirect observations were recently confirmed in three studies designed to test directly the hypothesis that Akt overexpression enhanced tumour cell invasive potential. Kim et al overexpressed Aktl in the HT1080 human fibrosarcoma sarcoma cell line and demonstrated that Akt induces expression and activation of matrix metalloproteinase (MMP)-9 via enhancement of NFKß activity, and that Aktl enhances cell migration in a PI3 kinase dependent manner. ${ }^{55}$ In this study, both endogenous and overexpressed Aktl were expressed primarily in the nucleus, and to a lesser extent at the cell membrane at the leading edge of the cell movement. In a similar study in murine breast cancer cells, Park et al recently demonstrated that breast cancer cells overexpressing Aktl showed enhanced invasive potential and increased expression and activity of MMP2, and that the invasive potential was MMP dependent. ${ }^{53}$ Finally, Higuchi et al demonstrated that Akt, but not the closely related PI3 kinase regulated protein SGK, mediated cell motility in PTEN knockout cells by a pathway that does not include phosphorylation of GSK3. ${ }^{56}$ Importantly, breast cancer prognosis has been recently correlated with activation of Akt. ${ }^{57}$ These data suggest a role for Aktl mediated MMP activation in tumour cell invasion, although the critical downstream targets responsible for this activity are uncertain and the localisation of activated Akt has not been well studied in human cancer tissues.

Owing to the central role of Akt in thyroid oncogene signalling and data supporting a potential mechanism for Akt in cancer cell motility and invasion, we hypothesised that Akt activation would be most significant in regions of thyroid cancer invasion and would be important in thyroid cancer cell motility. In the present study, we demonstrate that Akt activation is most pronounced in invasive regions of thyroid cancers, that subcellular localisation differs between papillary and follicular cancers, and that in vitro, nuclear activation of Akt is associated with thyroid cancer cell invasion.

\section{MATERIALS AND METHODS Reagents}

The antibodies used in this study were as follows. Anti-Akt (\#9272), anti-phospho-Akt (Ser473 IHC specific) (\#9277), anti-p44/42 MAP kinase (\#9102), and anti-phospho-p44/42 MAP kinase (\#9106) were purchased from Cell Signaling Technology (Beverly, MA, USA). Anti-Akt 1 (sc7126, sc1618, scl619, sc5298), anti-Akt 2 (sc 7127, sc5270), anti-Akt 3 (sc11520), anti-Ret (C-19), and anti-HA (sc 805) came from Santa Cruz Biotechnology (Santa Cruz, CA, USA). Upstate USA Inc (Charlottesville, VA, USA) supplied anti-Aktl (\#06558), anti-Akt2 (\#06-606), and anti-Akt3 (\#06-607), while anti-Aktl (\#610836, \#610876, \#610860) and anti-p27 were from BD Biosciences Pharmingen (San Diego, CA, USA). For studies of isoform specific expression, anti-Akt-1 (610836 and 610860; Pharmingen), anti-Akt-2 (06-606; Upstate USA Inc), and anti-Akt-3 (scl1520; Santa Cruz Biotechnology) were used based on preliminary experiments evaluating the degree of isoform specificity. Alexa Fluor 488 secondary antibody and ProLong Antifade Kit were from Molecular Probes (Eugene, OR, USA), and Vectastain Universal Quick kit, antigen unmasking solution, and DAB substrate kit were purchased from Vector Laboratories (Burlingame, CA, USA).

\section{Patients and tissue samples}

This project was approved by the institutional research committees of the individual institutions and informed consent was obtained from the patients. Tissue specimens were obtained from 66 patients ( 50 patients treated at the Ukrainian Center of Endocrine Surgery in Kiev and 16 patients treated at Ito Hospital and the Tokyo Women's Medical University, Tokyo). Tumours were classified as follicular adenoma (10 cases), atypical adenoma (10), follicular carcinoma (10), papillary carcinoma (26), and follicular variant of papillary carcinoma (10). Of the 50 patients from the Ukraine, 19 had had exposure to radiation fallout from the Chernobyl disaster, including 10 of 20 patients with papillary carcinoma $(n=20)$.

After fixation in $10 \%$ formalin and embedding in paraffin, $5 \mu \mathrm{m}$ thick serial sections were made for each specimen, which were then stained with haematoxylin and eosin and examined by two pathologists (VV and VS). Histological typing was based on World Health Organization criteria. Follicular adenomas (FA) exhibited a macro/microfollicular architecture comprising cells with small, round, equally sized, regularly spaced normochromatic nuclei. Atypical adenoma (AA) had microfollicular, solid or trabecular architecture comprising epithelial cells with one or more of the following nuclear features: overlapping, unevenly sized, irregular borders, pale chromatin, and prominent nucleoli. Vascular or capsular invasion was not found after examination of one inclusion block per $5 \mathrm{~mm}$ of tumour. No tumour displayed nuclear features typical of papillary cancers. Follicular carcinoma (FC) presented the same cytological features as atypical adenomas but in association with capsular or vascular invasion. Papillary carcinomas were subdivided into typical papillary carcinomas (PC) and follicular variant of papillary carcinomas (FVPC). Twelve patients, including two with FC, two with FVPC and eight with PC, had lymph node metastasis at the time of diagnosis.

\section{Immunohistochemical staining}

Sections were dewaxed, soaked in alcohol, and after microwave treatment in antigen unmasking solution for 10 minutes, incubated in 3\% hydrogen peroxide for 15 minutes to inactivate endogenous peroxidase activity. Then sections were incubated at $4^{\circ} \mathrm{C}$ overnight with anti-phospho-Akt (dilution 1:100), with anti-Akt, Akt 1, 2, 3 antibody (dilution 1: 200), with anti-Ret (C-19) (dilution 1:100), with anti-p44/42 MAP kinase (dilution 1:100), with anti-p27 (dilution 1:100). Immunostaining was performed using the Vectastain Universal Quick kit according to the manufacturer's instructions. Peroxidase staining was revealed with 3 , 3-diaminobenzidine. Antiserum was omitted in the negative control. Incubation with blocking peptide was performed to determine the specificity of Akt 1, 2, and 3 antibodies. Results were interpreted independently by three blinded investigators (VV, MS, MDR) and scored for the presence or absence of staining. Scoring was compared between the three investigators and agreement between two of the three investigators was required for a positive result to be determined (unanimity was achieved in all but two cases). 


\section{Immunofluorescence staining}

For immunofluorescence analysis, cells were grown on well slides (Labtek Inc), fixed with $3.7 \%$ formaldehyde for 10 minutes, permeabilised with $0.1 \%$ Triton X-100 for 15 minutes, and incubated in Vectastain blocking solution. Primary antibodies were applied for 1 hour at the same concentration as for immunohistochemical staining. Incubation with Alexa Fluor 488 conjugated secondary antibody (Molecular Probes Inc, Eugene, OR, USA) was carried out for 1 hour in the dark. Coverslips were mounted onto the slides with ProLong Antifade reagent, dried in the dark for 2 hours and then stored at $4^{\circ} \mathrm{C}$.

\section{Confocal microscopy}

Confocal images of follicular and papillary carcinoma tissue samples were collected using a Zeiss LSM 510 microscope equipped with a META spectral detector (Carl Zeiss Inc, Jena, Germany) in lambda mode and with a $\times 63$ Plan-Apochromat (NA 1.4) objective lens. A series of images or lambda stack (504-664 nm) was collected for each immunolabelled tissue sample, tissue samples stained with Alexafluor 488 conjugated antibody alone, and the unlabelled tissue samples (see supplemental figs A, B for an example of a lambda stack for papillary and follicular thyroid cancer samples, respectively). All image stacks were collected using the same image acquisition configuration. Pixel intensity values from regions of interest within the Alexafluor 488 only and unlabelled tissue samples were used to generate reference spectra of emission signatures for both Alexafluor 488 and autofluorescence from the tissue sample (see supplemental fig $\mathrm{C}$ ). The reference spectra were used to linearly separate the emission signals representative of Alexafluor 488 and autofluorescence in the immunolabelled tissue sample. A weighted linear separation algorithm provided by Zeiss in the LSM 510 operating software (version 3.0) was used for separation. Separation was also performed using the same two reference spectra with lambda stacks of the Alexafluor 488 only and unlabelled tissue sample to test the appropriate assignment of emission signal. The resultant separated images were exported individually as TIF files and processed for presentation in figures using Adobe Photoshop (version 5.02; Adobe Systems Inc., San Jose, CA, USA).

\section{DNA extraction and PCR amplification of ras genes}

After microdissection of tumour on slides, DNA was extracted using the QI-Amp DNA mini kit (Qiagen SA) according to the manufacturer's instructions. Sequences of the $H$-ras, $K$-ras, and $N$-ras oncogenes in exons 1 and 2 (designated $\mathrm{H} 1, \mathrm{H} 2, \mathrm{~K} 1, \mathrm{~K} 2, \mathrm{~N} 1, \mathrm{~N} 2$ ) were amplified using

Table 1 Ras oncogenes amplified, and primer sequences used

\begin{tabular}{|c|c|c|c|c|}
\hline Gene & Codon & Name & $\begin{array}{l}\text { Length } \\
\text { (bp) }\end{array}$ & Primer sequences \\
\hline \multirow[t]{2}{*}{ H-ras } & $12 / 13$ & $\mathrm{H} 1$ & 123 & $\begin{array}{l}\text { ATGACGGAATATAAGCTGGT } \\
\text { CCTTATAGTGGGGTCGTATT }\end{array}$ \\
\hline & 61 & $\mathrm{H} 2$ & 178 & $\begin{array}{l}\text { AGGTGGTCATTGATGGGGAG } \\
\text { AGGAAGCCCTCCCCGGTGCG }\end{array}$ \\
\hline \multirow[t]{2}{*}{$K$-ras } & $12 / 13$ & $\mathrm{~K} 1$ & 164 & $\begin{array}{l}\text { GGCCTGCTGAAAATGACTGAA } \\
\text { GGTCCTGCACCAGTAATATGC }\end{array}$ \\
\hline & 61 & K2 & 133 & $\begin{array}{l}\text { CAGGATTCCTACAGGAA } \\
\text { GCAAGTAG } \\
\text { CACAAAGAAAGCCCTCCCCA }\end{array}$ \\
\hline \multirow[t]{2}{*}{ N-ras } & $12 / 13$ & $\mathrm{~N} 1$ & 112 & $\begin{array}{l}\text { ATGACTGAGTACAAACTGGT } \\
\text { CTCTATGGTGGGATCATATT }\end{array}$ \\
\hline & 61 & N2 & 176 & $\begin{array}{l}\text { TCTAACAGAAAACAAGTGGT } \\
\text { GTAGAGGTAATATCCGCAA }\end{array}$ \\
\hline
\end{tabular}

Primer sequences are set out $5^{\prime}$ to $3^{\prime}$, with the first of each pair being forward, and the second reverse. the primer pairs listed (table 1). The PCR reaction mixture $(50 \mu \mathrm{l})$ contained 0.1 to $0.5 \mu \mathrm{g}$ of genomic DNA, $2 \mathrm{mmol} / \mathrm{l}$ or $1.5 \mathrm{mmol} / \mathrm{l} \mathrm{MgCl}_{2}$ for $\mathrm{Kl}$ and $\mathrm{Nl}$, or the other ras oncogenes respectively, $10 \times$ concentrated PCR-buffer (Qiagen), $200 \mu \mathrm{mol} / \mathrm{l}$ of deoxyribonucleoside triphosphate (dATP, dCTP, dGTP, dTTP), $200 \mathrm{nmol} / \mathrm{l}$ of each primer and $1.25 \mathrm{U}$ of HotStart Taq DNA Polymerase (Qiagen). Amplification was achieved on a Cyclogen Dri-block Cycler Techne (Cambridge Ltd). Following HotStart Taq DNA polymerase activation at $95^{\circ} \mathrm{C}$ for 15 minutes, templates were denatured at $94^{\circ} \mathrm{C}$ for 2 minutes. This initial step was followed by 30 to 38 cycles of PCR, each comprising 1 minute of denaturation at $94^{\circ} \mathrm{C}$, 1 minute of annealing (at $53^{\circ} \mathrm{C}$ for $\mathrm{N} 2,55^{\circ} \mathrm{C}$ for $\mathrm{Hl}$ and $\mathrm{Kl}$, $57^{\circ} \mathrm{C}$ for $\mathrm{H} 2$ and $\mathrm{N} 1$, and $58^{\circ} \mathrm{C}$ for $\mathrm{K} 2$ ), and 1 minute of extension at $72^{\circ} \mathrm{C}$. The extension step in the last cycle was 10 minutes. PCR products were submitted to electrophoresis on 3\% agarose gel in TAE buffer and stained with ethidium bromide. In all cases direct sequencing was performed using an Applied Biosystem 373XL sequencer according to the manufacturer's instructions on PCR products purified using a Qiagen gel extraction kit. In samples exhibiting mutations, both sense and antisense strands were sequenced for confirmation.

\section{Migration assays}

NPA cells were grown in RPMI medium with $10 \%$ FCS. After splitting, NPA cells were seeded in PRMI medium 10\% in a Boyden chamber $(8 \mathrm{~mm}$ pore). Simultaneous wells without membrane were used for growth of continuous cell culture in identical conditions. Incubation with LY294002 ( $5 \mu \mathrm{mol} / \mathrm{l})$ or PD98059 $(5 \mu \mathrm{mol} / \mathrm{l})$ was performed in a Boyden chamber and in continuous cell culture. After 24 hours, membrane were washed with PBS, cells were fixed in 3.7\% formalin for 10 minutes. Then membranes were subjected for immunohistochemical staining with phosphorylated Akt (pAkt), Akt 1, 2, and 3, and p27 antibodies as described above. To evaluate the degree of migration, microscopy was performed after elimination of cells from the lower side of the membrane (so that only non-migrated cells were present on the membrane) or after elimination of cells from the upper side of the membrane (so that only migrated cells were present on the membrane).

\section{RESULTS}

\section{Akt activation in benign thyroid tissues}

Sixty six normal thyroid slices were evaluated for their pattern of Akt activation by immunohistochemistry for total activated Akt using a non-isoform specific antibody for pAkt. No evidence of Akt activation was detected in 62/66 normal thyroid tissue samples, consistent with previously published data $^{6}$ (figs 1 and 2). From the same slides, or from slides stained at the same time, regions containing thyroid cancer or benign nodules demonstrated Akt activation, serving as positive controls.

Twenty benign thyroid follicular adenomas, including ten with regions of cellular atypia suggestive of possible premalignant changes, were examined for Akt activation. Six of the 10 tumours with atypia demonstrated activation of Akt while 2 of the 10 typical follicular adenomas had activation of Akt (fig l). Of note is that the Akt activation was noted only in atypical cells of the atypical adenomas, and near vessels in the typical follicular adenomas. Taken together, these data demonstrate that benign thyroid tissues rarely demonstrate immunoactive pAkt, except for atypical follicular adenomas.

\section{Akt activation in malignant thyroid tissues}

Follicular carcinomas have previously been demonstrated by Western blot analysis to have greater levels of Akt activation compared with both normal tissue and papillary thyroid cancers. ${ }^{6}$ We evaluated 10 follicular carcinomas by 

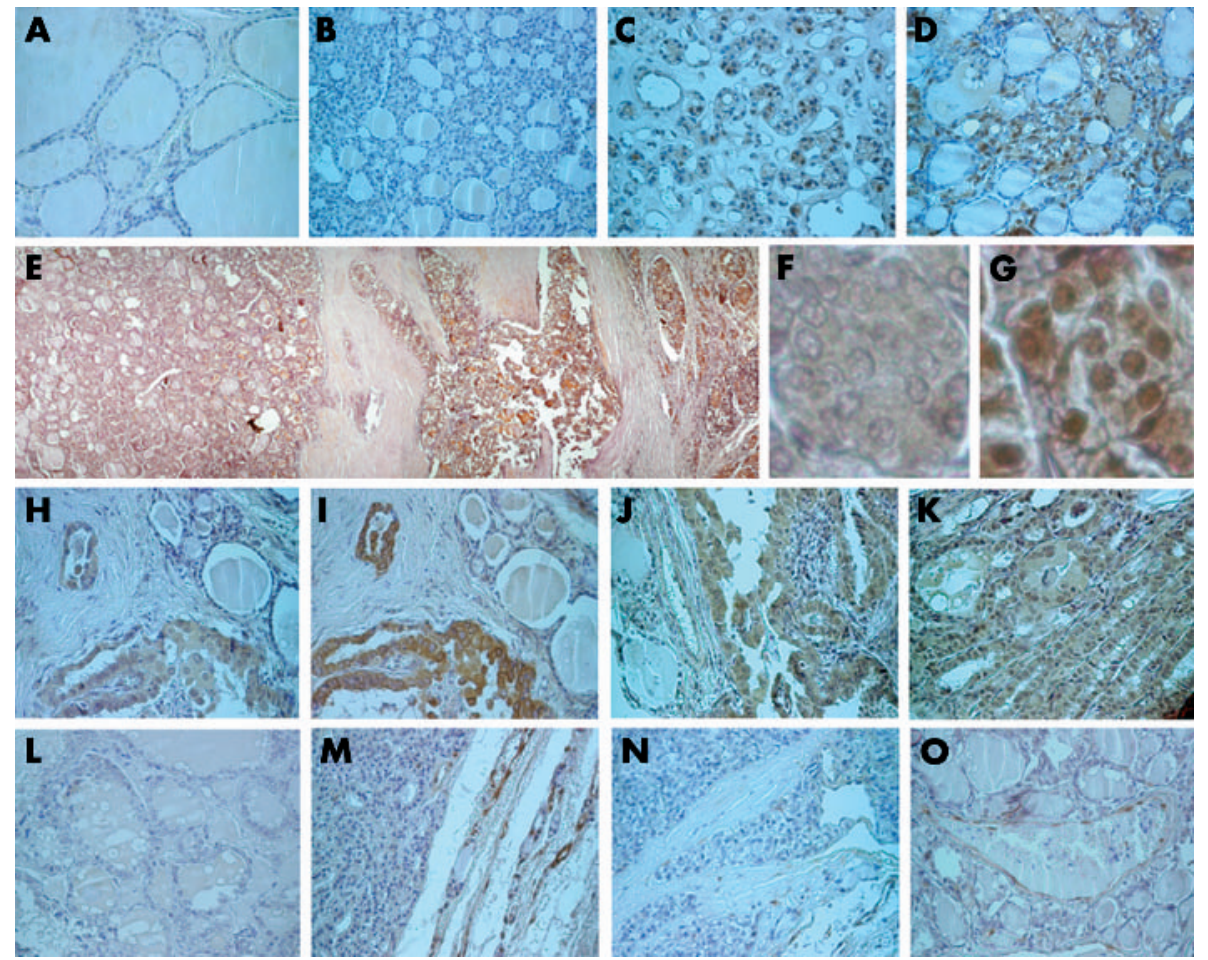

Figure 1 Phosphorylated Akt (pAkt) and ERK (pERK), and Ret immunostaining in thyroid tissues. Immunhistochemistry was performed using primary antibodies that recognise total pAkt regardless of isoform, pERK (42/44), and the tyrosine kinase domain of Ret. In normal thyroid tissue (A) and the central regions of benign follicular adenomas (B), no immunoreactive pAkt was detected; however, nuclear pAkt was detected in the pericapsular regions of some benign follicular adenomas $(C)$, and benign follicular adenomas with cellular atypia (D). In follicular carcinomas, pAkt was detected at low levels in the central regions of follicular carcinomas and at higher levels in regions of capsular invasion ( $E$, low magnification). High power views from the same tumour demonstrate low levels of immunoreactive pAkt in the central regions $(F)$ compared with high levels of nuclear immunoreactive pAkt in cells from the invasive regions (G). In papillary carcinomas, pAkt immunostaining demonstrated cytoplasmic localisation of activated Akt in non-invasive regions of papillary thyroid cancers (H) that correlated with Ret activation (I). No expression of Akt or Ret is seen in the adjacent normal tissue. However, both nuclear and cytoplasmic activation of Akt was demonstrated in invasive regions of papillary cancers $(\mathrm{J})$ and in lymph node metastases from the same tumour (K). No activation of Akt was demonstrated in samples of Ret negative follicular variant of papillary thyroid carcinoma expressing Ret (L). Slight pERK immunostaining was detected only in papillary thyroid cancers (M). By contrast, pERK was not detected in either follicular adenomas (N) or carcinomas (O). Endothelial cells within the same slices demonstrated immunoreactive $p E R K$ (M and O).

immunohistochemistry for pAkt. Focal activation of Akt was noted in the regions of capsular and vascular invasion in all 10 primary follicular carcinomas (fig 1), and in metastatic cancer tissue from local lymph nodes and distant sites (two cases). By contrast, the central regions of the tumour that were not invasive demonstrated much less immunoreactive pAkt (fig 1). Immunohistochemical analysis was also performed for activated ERK using an antibody specific for phosphorylated ERK (pERK). In all cases, minimal amounts of immunoactive pERK were identified in the thyroid tumour cells compared with vascular endothelial cells from the same tissue samples (fig 1). Activating mutations of the $\mathrm{H}_{-}, \mathrm{N}_{-}$, and $K$-ras genes were evaluated by direct sequencing after PCR from DNA derived from paraffin embedded tissue. Point mutations (A-G) at codon 61 of $N$-ras were detected in 3/10 follicular cancers. There were no obvious differences in immunoactive pAkt or pERK in the tumours with or without activating mutations of Ras (fig 1).

Thirty six papillary thyroid cancers were examined for immunohistochemical evidence of Akt activation, including 10 FVPC, 21 typical papillary cancers, and 5 poorly differentiated papillary cancers characterised by tall cells or a solid growth pattern. Western blots were also performed from 14 of these 36 cases. Activation of Akt was detected in all 21 cases of typical papillary cancer and all five poorly differentiated tumours (fig 2). By contrast, only 2/10 FVPC tumours demonstrated activation of Akt. The intensity of immunoactive pAkt was greatest in regions of invasion and in lymph node metastases, similar to the follicular cancers (fig 1).

Of the typical and poorly differentiated papillary cancers, 10 cases evaluated for overexpression of Ret by immunohistochemistry were patients who had been exposed to radiation at Chernobyl (mean latency between exposure and thyroid surgery was 13.2 years); 8/10 displayed overexpression of the tyrosine kinase domain of Ret, a marker of RET/PTC gene rearrangement (fig 1). In all eight cases, RT-PCR analysis of isolated total RNA confirmed the presence of RET/PTCI or 3 gene rearrangements. Of the two FVPC cases that displayed increased immunoactive pAkt, Ret overexpression was identified in one case and an activating mutation of $N$-ras in the other (data not shown). Activation of ERK was not detected within the FVPC thyroid cancer tissue.

Fourteen cases of papillary cancer were studied by both immunohistochemistry and immunoblotting for levels of total and pAkt (fig 2). With immunohistochemistry, increased levels of immunoactive pAkt were observed in the invasive regions of papillary cancers and in local nodal metastases in all 14 cases. For immunoblotting, tumour tissue was snap frozen in liquid nitrogen and total protein lysates were isolated. Compared with adjacent normal tissue, greater levels of phosphorylated Akt were demonstrated by Western blot in 12 of the 14 cases (fig 2B). In the two cases with discordant immunohistochemistry and immunoblotting results, a very localised pattern of Akt activation limited to invasive regions of the cancers was identified by 
A

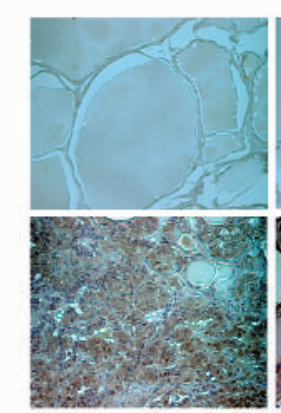

B

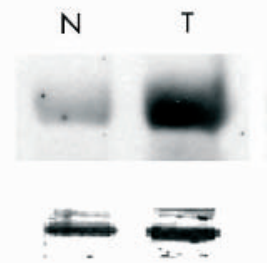

\#2

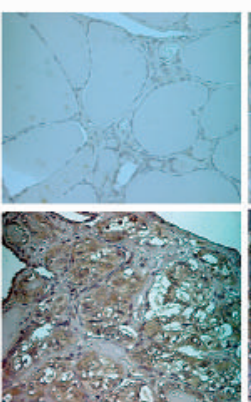

N T
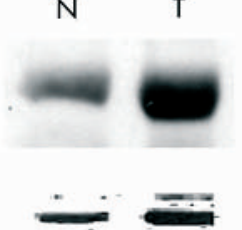

\#3
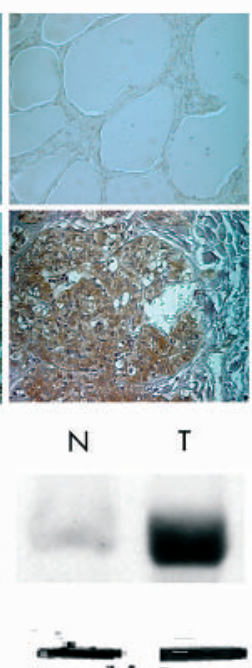

\#4

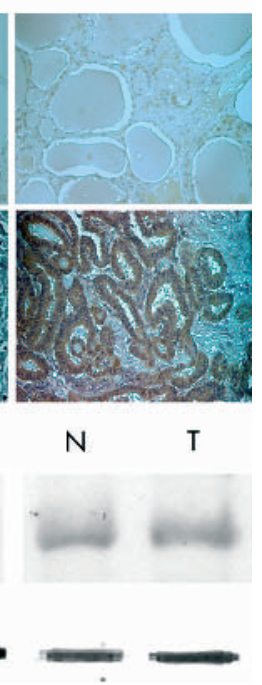

Figure 2 Akt activation in invasive papillary thyroid cancer. Immunohistochemistry and immunoblottting were performed on paraffin embedded and fresh frozen tissue samples obtained from invasive papillary thyroid cancers and adjacent normal tissue. In all cases, invasive regions of the papillary cancers demonstrated marked Akt activation by immunohistochemistry compared with adjacent normal tissue. Similarly, immunoblotting demonstrated overactivation of Akt in 12 of 14 examined samples. Representative data are shown. (A) Top, normal; bottom, tumour. (B) Top, pAKT; bottom, tubulin. immunohistochemistry. Because the protein lysates were prepared from a non-microdissected piece of the tumour, the focal enhanced activation may not have been identified by immunoblotting. However, taken together, the immunohistochemical and immunoblotting data both demonstrate overactivation of Akt in thyroid cancer tissue, and the immunohistochemical pattern demonstrates an association with tumour invasion.

\section{Subcellular localisation of activated Akt in thyroid cancer}

Differences were noted in the subcellular localisation of activated Akt in follicular $v$ papillary thyroid cancers by immunohistochemistry (compare fig 1 panels $\mathrm{E}$ and $\mathrm{F}$ with I and $J$ and with fig 2). Primarily, nuclear localisation of immunoactive pAkt was detected in the invasive cells from follicular thyroid cancers and in the atypical cells in benign follicular adenomas. By contrast, cytoplasmic localisation was characteristic of the papillary thyroid cancers. Only in the invasive and metastatic regions of the papillary cancers was nuclear immunofluorescent staining noted in conjunction with cytoplasmic pAkt. To confirm and extend these findings, confocal microscopy was performed for three papillary and follicular cancers, and for follicular adenomas (fig 3 depicts representative data). An association was observed between the subcellular localisation of activated Akt and the histological subtype of thyroid cancer in all cases examined; namely, cytoplasmic activated AKT was observed in papillary thyroid cancers, while nuclear localisation of pAkt was observed in follicular thyroid cancer.

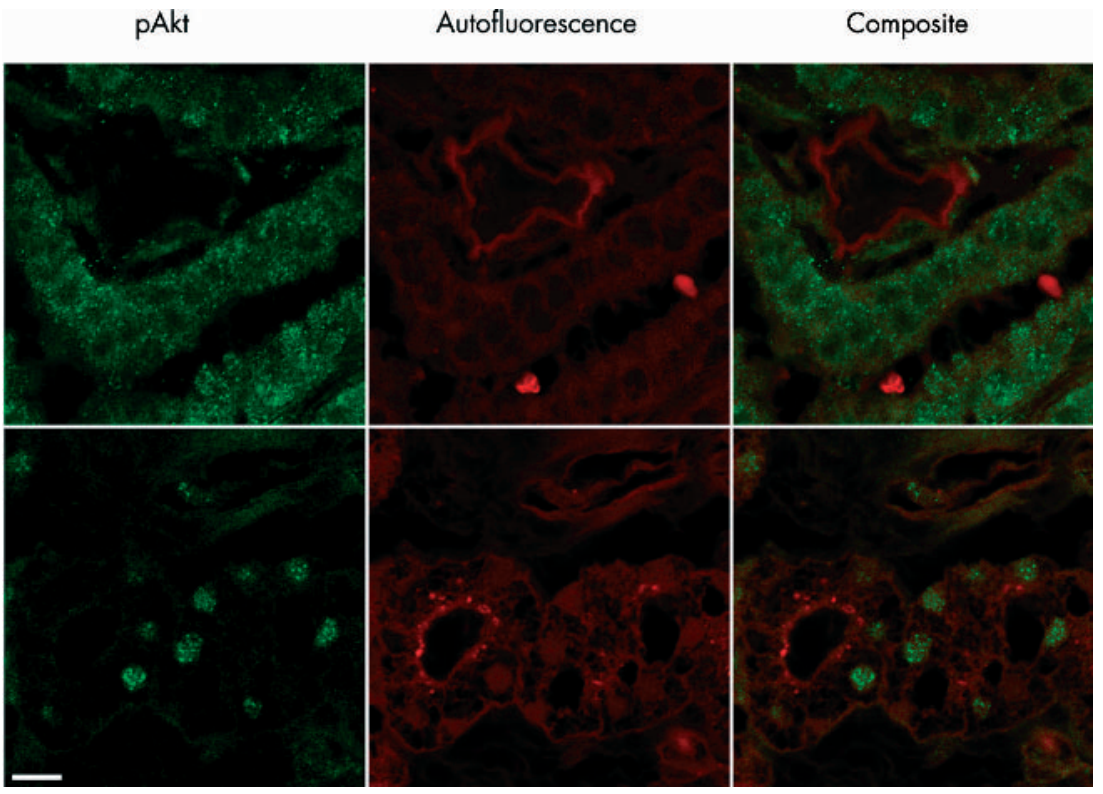

Figure 3 Confocal microscopy (CM) of pAkt in papillary and follicular thyroid cancer. To clarify the apparent differences in pAkt subcellular localisation between papillary and thyroid cancers noted on immunohistochemical analysis, confocal microscopy was performed on three papillary cancer, three follicular cancer, and three follicular adenoma samples. Representative data of confocal images of Akt distribution in papillary (top) and follicular (bottom) carcinoma tissue samples are demonstrated. The spectrally separated Alexafluor 488 tagged distribution of Akt in follicular and papillary carcinoma tissue (green, left column) and intrinsic tissue sample autofluorescence (red, middle column), and composites of two resultant separated images (right column) are shown. Scale bar represents $\sim 10 \mu \mathrm{m}$. Marked cytoplasmic localisation of immunoactive pAkt was detected in papillary cancer, while follicular cancers demonstrated a nuclear pattern. 
Tumour invasion is associated with cytoplasmic p27 expression in thyroid cancer

One of the phosphorylation targets of Akt is p27, phosphorylation of which results in nuclear exclusion of the protein, resulting in enhanced cellular proliferation. Recent data have associated cytoplasmic overexpression of p27 with Akt activation and aggressive behaviour in breast cancer. ${ }^{58-61} \mathrm{We}$ therefore determined if cytoplasmic expression of p27 correlated with tumour invasion and/or Akt activation and localisation in the thyroid cancer samples. ${ }^{62}$ In all cases examined (10 follicular cancers and 10 papillary cancers), cytoplasmic accumulation of p27 was identified in invasive tumour cells (fig 4), but it was not detected in thyroid cancer regions that did not demonstrate activated Akt or in adjacent normal thyroid tissue from the same slides. This was particularly evident in invasive cells that had nuclear activation of Akt (fig 4). Thus, in all cases examined, regions of invasive thyroid cancer were characterised by both nuclear immunoactive pAkt and cytoplasmic p27.

\section{Akt 1 is the principal activated form of Akt in thyroid cancer}

In previous work, we demonstrated by immunoblotting that both Akt 1 and Akt 2 proteins are overexpressed in follicular thyroid cancer compared with normal tissue; ${ }^{6}$ however, the isoform responsible for the overactivation has not been clarified. We therefore performed a series of experiments to determine which of the isoform specific antibodies demonstrated the greatest degree of isoform specificity. HEK-293 cells were transiently transfected with a plasmid containing haemaglutanin (HA) tagged Akt 1, 2, or 3 under control of the CMV promoter (generous gifts of Masahiro Aoki MD PhD, Scripps Institute, La Jolla, CA, USA). Whole cell protein lysates were prepared and subjected to immunoprecipitation using an anti-HA antibody 48 hours after transfection. The precipitated proteins were then evaluated for Akt 1, 2, and 3 protein expression using a variety of commercially available antibodies as described above. Subsequent experiments using embryonic fibroblasts from Akt l knockout cell lines (generous gifts of $\operatorname{Dr} M$ Birnbaum, University of Pennsylvania, Philadelphia, PA, USA) were used to confirm the specificity of the immunohistochemical method using those antibodies (data not shown). Using the most specific available antibodies ( $>90 \%$ detection of isoform specific immunoprecipitant), immunohistochemical analysis was

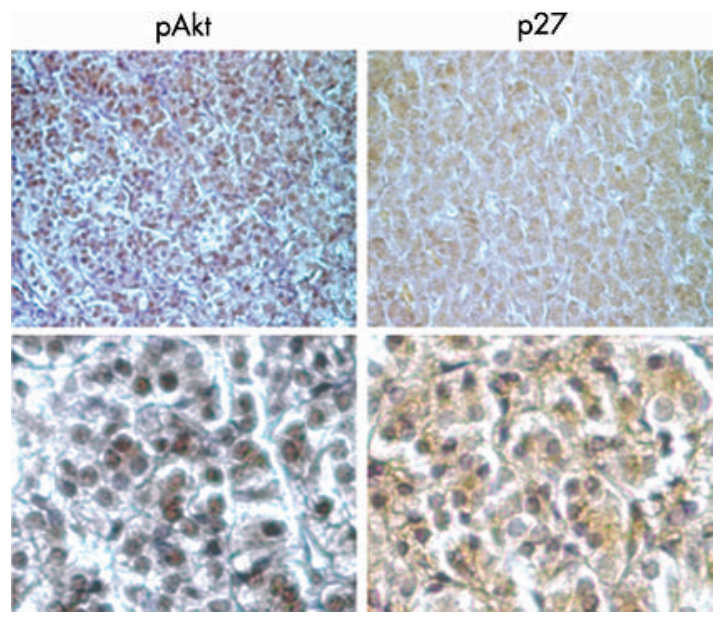

Figure 4 p27 immunostaining in invasive areas of thyroid cancer. Immunohistochemistry of invasive regions of thyroid cancers are characterised by cytoplasmic localisation of $\mathrm{p} 27$ and nuclear localisation of activated Akt from the same regions of capsular invasion of the same tumour (original magnification: top, $\times 100$; bottom, $\times 400$ ). performed for expression of Akt 1, 2, and 3 as well as phosphorylated total Akt in 38 cases (summarised in table 2). Representative results for follicular adenomas, papillary carcinomas, and follicular carcinomas are shown in fig 5 and summarised in table 1 .

In follicular adenomas, total phosphorylated Akt was found in nucleus of atypical follicular cells, and Akt 1 and 2 co-localised to the nucleus; no AKT3 was detected. In follicular cancers, expression of all three Akt isoforms was consistently demonstrated. Activated total Akt was demonstrated to localise primarily in the nucleus of these tumours, and, while all three Akt proteins were expressed, only Akt 1 co-localised to the nucleus (fig 5, table 1). Papillary cancers demonstrated primarily cytoplasmic activated Akt, except in invasive regions where cytoplasmic and nuclear pAkt was identified. The papillary cancers consistently demonstrated only Akt 1 expression. Akt isoform specific quantitative RTPCR analysis was performed as previously described, ${ }^{6}$ using total RNA isolated from several poorly differentiated cancers from which larger amounts of tissue were available. In all cases, higher amounts of Akt 1 mRNA than Akt 2 or 3 were detected, consistent with the immunohistochemical data (data not shown). Taken together, these data support the conclusion that in the evaluated thyroid cancer tissue, Akt 1 is the principal overexpressed and overactivated isoform of Akt in thyroid cancer. In contrast to malignant follicular carcinomas, benign atypical follicular adenomas demonstrate nuclear expression of both Akt 1 and 2 (fig 5, table 1).

\section{Nuclear activated Akt is associated with thyroid cancer motility in vitro, which is PI3 kinase dependent} We evaluated several human thyroid cancer cell lines for their ability to migrate in Boyden chamber assays. One particular cell line, NPA-87, a poorly differentiated human thyroid cancer cell line, demonstrated rapid movement of the cells through the membrane, and subsequent migration to the bottom of the chamber, leading to growth of the migrated cells on the bottom of the well. Therefore, this cell line was chosen for the subsequent migration experiments.

Simultaneous experiments were performed in triplicate on at least three separate occasions. Following addition of the cells to the membrane, immunostaining for Akt isoforms, pAkt, and p27 was performed on cells on the top and bottom surfaces of the membrane, and at the bottom of the Boyden chamber well to represent pre-migrated, migrated, and postmigrated cell populations. For comparison, immunostaining was performed on NPA cells grown in identical medium conditions in cell culture dishes (non-migrated control cells). The cells that migrated to the bottom of the membrane demonstrated nuclear Akt 1 (but not Akt 2 or 3) activation, similar to the invasive papillary thyroid cancers (fig 6). The

Table 2 Summary of localisation of activated Akt and Akt isoforms in 38 thyroid cancer samples

\begin{tabular}{|c|c|c|c|c|c|c|c|c|}
\hline & \multicolumn{2}{|c|}{ pAkt } & \multicolumn{2}{|c|}{ Akt 1} & \multicolumn{2}{|c|}{ Akt 2} & \multicolumn{2}{|c|}{ Akt 3} \\
\hline & Nuc & Cyto & Nuc & Cyto & Nuc & Cyto & Nuc & Cyto \\
\hline FA (typical) $(n=3)$ & 0 & 0 & 0 & 0 & 2 & 1 & 0 & 0 \\
\hline $\begin{array}{l}\text { FA (atypical) } \\
(n=10)\end{array}$ & 6 & 1 & 6 & 0 & 6 & 6 & 0 & 3 \\
\hline $\mathrm{FC}(\mathrm{n}=11)$ & $7^{*}$ & 8 & $7^{*}$ & 9 & 1 & 11 & 0 & 7 \\
\hline$P C(n=14)$ & $2 \dagger$ & 10 & $2 \dagger$ & 10 & 2 & 7 & 0 & 0 \\
\hline
\end{tabular}

*In regions of invasion, nuclear pAkt and Akt 1 were identified. thn regions of invasion $(n=8)$ nuclear immunoactive pAkt and Akt 1 (but not Akt 2) were demonstrated and cytoplasmic pAkt, Akt 1, and Akt 2 were maintained.

Note that some tumours displayed both nuclear and cytoplasmic staining while others displayed only one type of staining. 


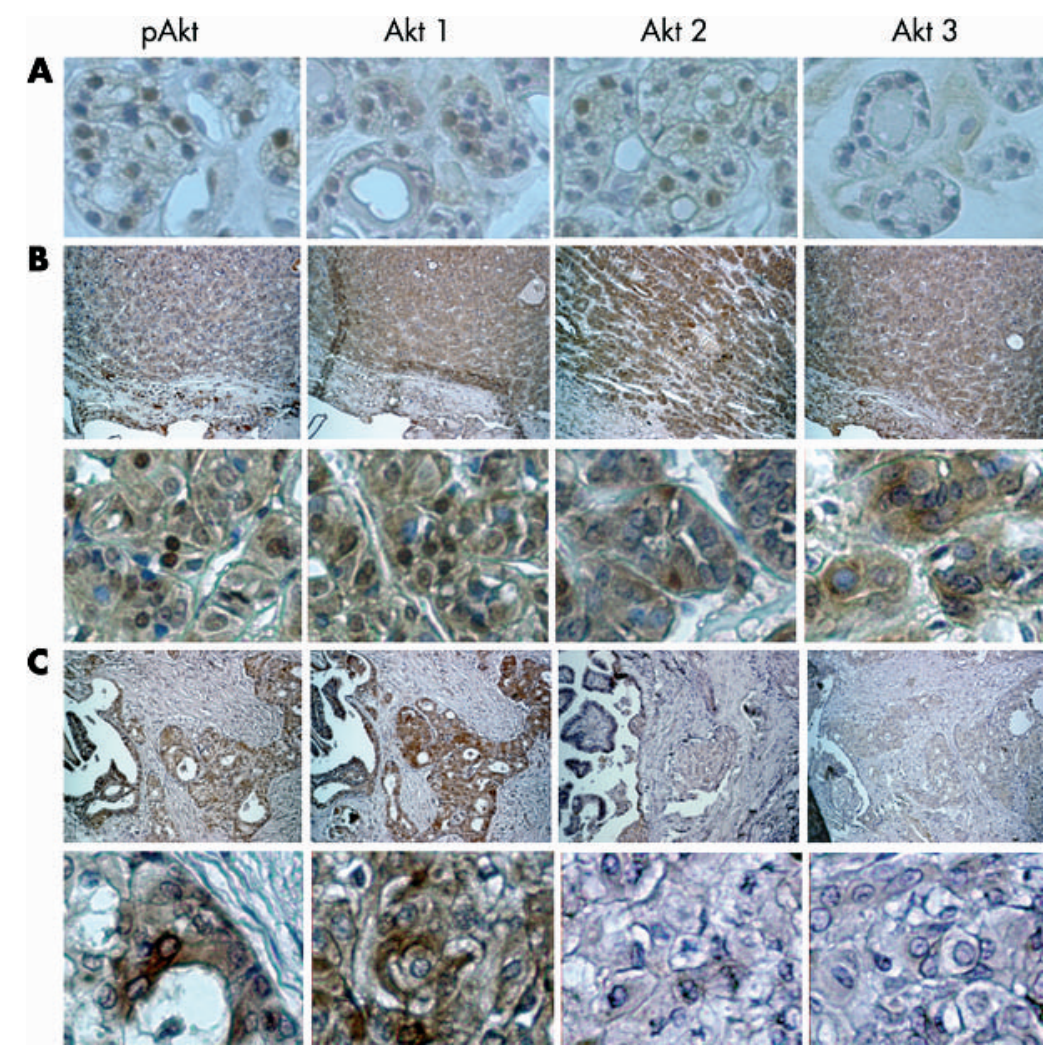

Figure 5 Akt isoform activation in thyroid tumours. Representative data are demonstrated. Total pAkt, Akt 1, Akt 2, and Akt 3 immunostaining were performed on follicular adenomas with (A) atypical $(\times 400)$, (B) follicular (top, $\times 100$; bottom, $\times 400)$, and $(C)$ papillary (top, $\times 100$; bottom,$\times 400$ ) cancers. The data for the group are summarised in table 1. Nuclear pAkt was demonstrated in the atypical follicular adenomas that correlated with Akt 1 and 2 localisation. Primarily, nuclear pAkt was demonstrated in follicular cancer, and while all three isoforms were expressed, only Akt 1 was located in the nucleus. Papillary cancers were characterised primarily with cytoplasmic pAkt, and Akt 1 was the principal expressed Akt isoform.

NPA cells that migrated to the bottom of the chamber demonstrated a striking nuclear localisation of immunoactive pAkt (fig 7A). To determine if the nuclear activation of Akt correlated with cytoplasmic localisation of immunoactive p27, the migrated NPA cells were evaluated for p27 expression by immunohistochemistry. In these cells, immunoactive p27 was localised entirely in the cytoplasm (fig 7A). By contrast, the control NPA cells grown in cell culture conditions identical to the migrated cells, which did not migrate through a membrane, demonstrated both nuclear and cytoplasmic immunoactive Akt and p27 (fig 7A).

The regulation of NPA cell migration was assessed using blockers of PI3 kinase (LY294002) and MEK (PD98059) at low doses. The ability of the cells to migrate was inhibited by incubating cells with a low dose of LY294002 (5 $\mu \mathrm{mol} / \mathrm{l}$, fig 7C). In NPA cells, this dose is not growth inhibitory, but effectively blocks Akt phosphorylation (Ringel et al, unpublished observations). In contrast, treatment with non-growth inhibiting doses of PD98059 blocked ERK phosphorylation, but did not inhibit cell migration (fig 7B). Moreover, consistent with inhibition of migration, p27 was located in both the cytoplasm and nucleus in LY294002 treated NPA cells (data not shown). These data suggest that activation of PI3 kinase, but not MEK, is necessary for migration of NPA cells in the Boyden chamber assay.

\section{DISCUSSION}

Akt activation is known to be involved in thyroid tumorigenesis in Cowden's syndrome, via inactivation of PTEN, and overactivation of Akt has been demonstrated in sporadic thyroid cancers. ${ }^{4-6}$ Moreover, many thyroid oncogenes are known to activate several downstream signalling pathways, including PI3 kinase and Akt, suggesting the potential for a central role for Akt in thyroid tumorigenesis. These data, however, do not address either the isoform specificity of this overactivation or whether Akt activity is involved in thyroid

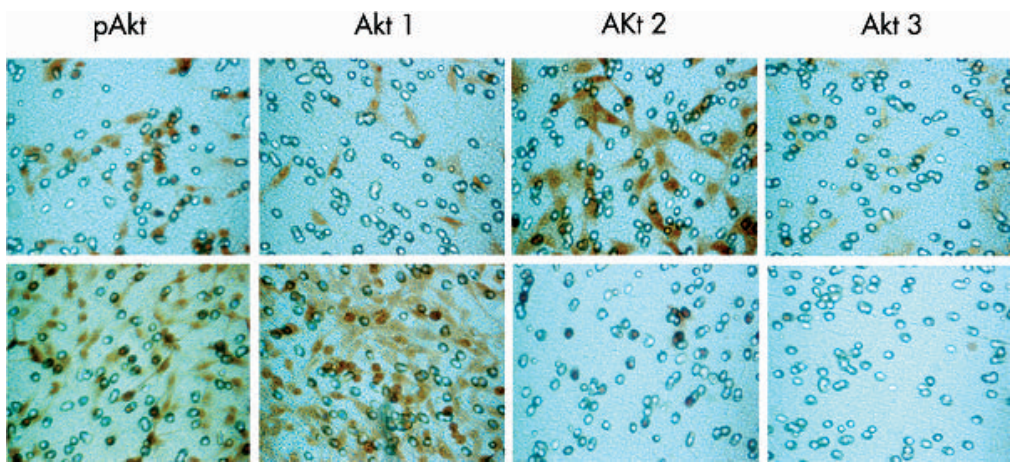

Figure 6 Akt activation and Akt isoform expression in migrating NPA thyroid cancer cells. NPA thyroid cancer cells were grown in Boyden chambers. Prior to migration, cytoplasmic activated Akt is predominant (top), as are Akt 1 and 2. Akt 1 is primarily cytoplasmic. After migrating to the lower side of the membrane (bottom), the cells show more prominent pAkt staining in the nucleus, and there is a predominance of Akt 1 in the nucleus. 
A
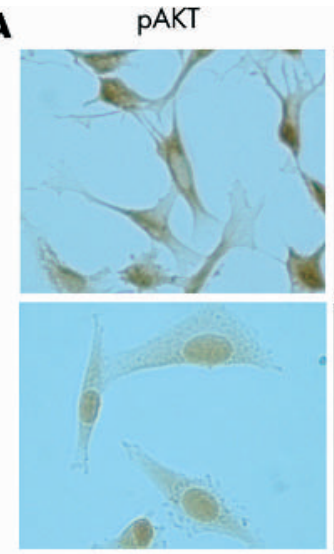

B

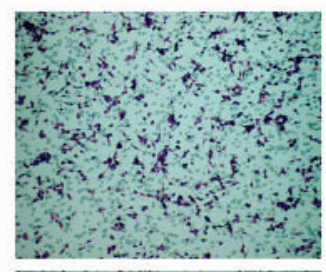

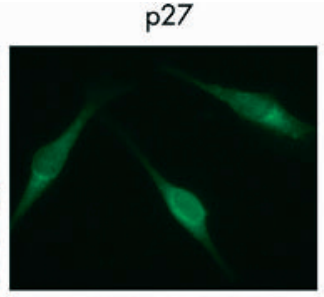

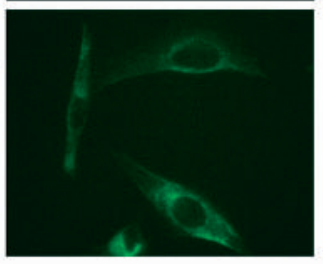

LY294002

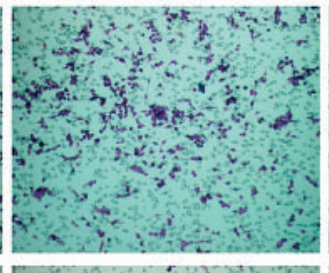

PD98059

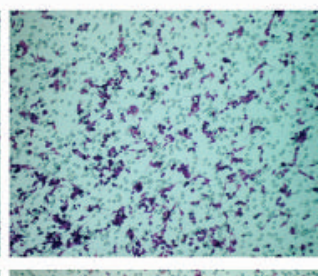

Figure 7 NPA thyroid cancer cell migration is dependent on PI3 kinase and is associated with altered localisation of pAkt and p27. (A) Nonmigrated cells (top) demonstrate cytoplasmic and some nuclear pAkt and nuclear, peri-nuclear, and cytoplasmic p27. By contrast, the migrated cells (bottom) demonstrate completely nuclear pAkt and completely cytoplasmic p27 expression. (B) The ability of the NPA cells to migrate is inhibited by non-growth inhibitory doses of LY294002, but not PD98059 (data are representative of three independent experiments performed in triplicate; top, all cells; bottom, migrated cells).
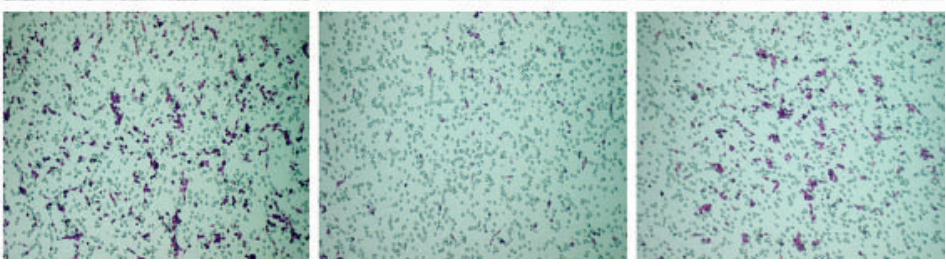

cancer progression, both critical issues when defining molecular targets for therapy.

In the present study, we have demonstrated by immunohistochemical analysis that normal thyroid tissue and typical benign thyroid adenomas rarely display Akt activation, similar to previously published data from Western blotting analysis. ${ }^{6}$ However, we have noted that the atypical regions of benign, but atypical follicular adenomas frequently display nuclear Akt activation, similar to that noted in the invasive regions of follicular thyroid cancers. This correlation suggests that these cells may represent pre-malignant cells in the proposed follicular adenoma-carcinoma sequence for follicular thyroid tumorigenesis. ${ }^{1}$ In addition, compared with follicular and papillary thyroid cancers, only the atypical follicular adenomas demonstrated both Akt 1 and Akt 2 immunostaining in the nucleus. The importance of switching to primarily Akt 1 activation is uncertain, but it does match the pattern noted in the cell migration assays using NPA thyroid cancer cells (fig 6).

The finding that follicular carcinoma cells invading into the tumour capsule or blood vessels, or metastasising to other areas, were characterised by Akt activation in a nuclear pattern suggests an association between Akt activity and tumour aggressiveness. This finding appears to be specific for invading cells, as it is not found in the central regions of the tumours. The mechanisms that regulate Akt activation and localisation during invasion are uncertain and are probably multifactorial; however, in vitro studies using the NPA cell line suggest that PI3 kinase and Akt activation may be mechanistically important in thyroid cancer cell migration. These data, in addition to the apparent isoform specificity of Akt in the invading cells, suggest that Akt 1 may represent an attractive target for preventing or treating aggressive follicular thyroid cancers. As our prior studies demonstrated overexpression of Akt 1 and 2 in thyroid cancers, some of the overactivation could relate to overexpression of Akt isoforms in thyroid cancers. Finally, the demonstration that nuclear exclusion of p27, a marker of breast cancer invasiveness that can be a consequence of Akt activation, ${ }^{58-61}$ correlated with enhanced Akt activation and nuclear localisation in vivo and in vitro also suggests a role for Akt activation in thyroid tumour cell invasion. Taken together, the data support a role for the intracellular localisation of activated Akt, and perhaps the specific activated isoform, in determining the cellular effects of Akt in thyroid cancer cells.

In papillary thyroid cancer, it is of interest that cancers with overexpression and gene rearrangements involving Ret demonstrated the greatest levels of overactivation of Akt. In this case, the activated Akt was cytoplasmic and was found throughout the tumour, although higher levels were noted in the invasive regions of the tumours. Moreover, in these regions of invasion, most of the cancer cells demonstrated both nuclear and cytoplasmic Akt, again suggesting that nuclear activated Akt is associated with invasion, even in the setting of ret gene rearrangements. The global activation of Akt in the Ret/PTC expressing tumours is consistent with data demonstrating that Ret tyrosine kinase signals in part through PI3 kinase ${ }^{17} 192163$ and is clearly distinct from nonRet/PTC expressing papillary cancers and follicular cancers that demonstrate activation of Akt focally in the invasive regions of the thyroid tumours, but not globally in all cells. The RET activated tumours did not demonstrate significant phosphorylation of ERK, suggesting preferential activation of Akt by Ret/PTC, similar to data from Ret/PTC3 
over-expressing thyroid cells (Saji and Ringel, unpublished observations).

Because these observations are based primarily on immunohistochemistry, we used Western blotting to evaluate a subset of the tumours and normal tissue of proteins isolated at the time of surgery as well as by immunohistochemistry. In these tumours, overall levels of Akt activation were higher in 12 of 14 tumours by Western blotting, while all 14 demonstrated Akt overactivation by immunohistochemistry. The two discrepant results were from tumours with very focal Akt activation in the invasive regions only that did not have immunohistochemical evidence of Ret activation. Because the tumour tissue was not microdissected prior to protein isolation form the frozen samples, it is likely that the Western blot was too insensitive to detect this difference. Microdissection of tumours, followed by subcellular protein fractionation, is planned for the future, providing that enough protein is available from the tumour samples.

To determine if there is a functional role for PI3 kinase activation in thyroid cancer cell motility, we developed an in vitro model of thyroid cancer cell motility using NPA poorly differentiated thyroid cancer cells. Consistent with the finding of increased nuclear activated Akt in the invasive regions of papillary cancers, NPA cell migration was associated with near complete nuclear localisation of activated Akt, while non-migrated cells grown in identical culture conditions displayed both nuclear and cytoplasmic activation of Akt. In addition, the migration of the cells was associated with cytoplasmic localisation of immunoactive p27, thus correlating cell migration, nuclear activation of Akt, and cytoplasmic p27.

To test for a functional role of pathway activation, thyroid cancer cells were incubated with low dose LY294002 and PD98059, inhibitors of PI3 kinase and MEK, respectively, to evaluate the effects of pathway inhibition on cell migration. Because in our preliminary studies there was an apparent relationship between cell number, cell growth, and cell migration, we used a low dose of inhibitors that does not affect NPA cell growth as measured by thymidine incorporation into DNA and cell counting (Ringel et al, unpublished observation). Using these low doses, we demonstrated that inhibition of PI3 kinase completely blocked both the ability of NPA cells to migrate and the cytoplasmic limited expression of p27 detected in the migrated cells, while MEK inhibition had no effect. These data suggest a specific functional role for PI3 kinase activity in NPA cell migration.

In conclusion, we have demonstrated that activation of Akt, particularly Akt 1 , is associated with tumour invasion and metastasis in follicular and papillary thyroid cancer, and with cellular atypia in apparently benign follicular adenomas. In addition, the localisation of activated Akt differs between the two forms of thyroid cancer, but nuclear localisation is associated with tumour invasion in both subtypes. Functionally, NPA human thyroid cancer cells demonstrate a PI3 kinase sensitive motility in vitro that is associated with nuclear exclusion of p27. In sum, these data suggest that activation of Akt 1 plays an important role in the progression of thyroid cancer, supporting the notion that it represents an attractive target for therapy of this disease.

\section{ACKNOWLEDGEMENTS}

This work was funded by grants from The American Cancer Society (RSG CNE102123) and The National Cancer Institute (CAN 8335479) to M D Ringel. We would like to acknowledge the help of Dr D Singer for review and discussion of the data.

\footnotetext{
Authors' affiliations

V Vasko, M Saji, M D Ringel, Ohio State University School of Medicine and Arthur G. James Cancer Center, Columbus, OH, USA
}

V Vasko, M Saji, E Hardy, K D Burman, M D Ringel, MedStar Research Institute/Washington Hospital Center, Washington DC, USA

V Vasko, A Larin, V Savchenko, Center for Endocrine Surgery, Kiev, Ukraine

V Vasko, C De Micco, INSERM U555, Mediterranean University, Marseilles, France

Michael Kruhlak, National Cancer Institute, National Institutes of Health, Bethesda, MD, USA

M Miyakawa, O Isozaki, H Murakami, T Tsushima, Tokyo Women's Medical University, Tokyo, Japan

\section{REFERENCES}

1 Fagin JA. Minireview: Branded from the start-distinct oncogenic initiating events may determine tumor fate in the thyroid. Mol Endocrinol 2002;16:903-11

2 Mazzaferri EL, Jhiang SM. Long-term impact of initial surgical and medical therapy on papillary and follicular thyroid cancer. Am J Med 1994:97:418-28

3 Sherman SI, Brierley JD, Sperling M, Ain KB, Bigos ST, Cooper DS Haugen BR, Ho M, Klein I, Ladenson PW, Robbins J, Ross DS, Specker B, Taylor T, Maxon HR 3rd. Prospective multicenter study of thyroid carcinoma treatment: initial analysis of staging and outcome. National Thyroid Cancer Treatment Cooperative Study Registry Group. Cancer 1998;83:1012-21.

4 Dahia PLM, Marsh DJ, Zheng Z, Zedenius J, Komminoth P, Frisk T, Wallin G, Parsons R, Longy M, Larsson C, Eng C. Somatic deletions and mutations in the Cowden disease gene, PTEN, in sporadic thyroid tumors. Cancer Res 1997:57:4710-13

5 Liaw D, Marsh DJ, Li J, Dahia PL, Wang SI, Zheng Z, Bose S, Call KM, Tsou HC, Peacocke M, Eng C, Parsons R. Germline mutations of the PTEN gene in Cowden disease, an inherited breast and thyroid cancer syndrome. Nat Genet 1997:16:64-7.

6 Ringel MD, Hayre N, Saito J, Saunier B, Schuppert F, Burch H, Bernet V, Burman KD, Kohn LD, Saji M. Overexpression and overactivation of Akt in thyroid carcinoma. Cancer Res 2001;61:6105-11.

7 Kimura T, Dumont JE, Fusco A, Golstein J. Insulin and TSH promote growth in size of $\mathrm{PC} \mathrm{Cl} 3$ rat thyroid cells, possibly via a pathway different from DNA synthesis: comparison with FRTL-5 cells. Eur J Endocrinol 1999;140:94-103.

8 Coulonval K, Vandeput F, Stein RC, Kozma SC, Lamy F, Dumont JE. Phosphatidylinositol 3-kinase, protein kinase B and ribosomal S6 kinases in the stimulation of thyroid epithelial cell proliferation by cAMP and growth factors in the presence of insulin. Biochem J 2000;348:351-8.

9 Kimura T, Van Keymeulen A, Golstein J, Fusco A, Dumont JE, Roger PP. Regulation of thyroid cell proliferation by TSH and other factors: a critical evaluation of in vitro models. Endocr Rev 2001;22:631-56.

10 Saito J, Kohn AD, Roth RA, Noguchi Y, Tatsumo I, Hirai A, Suzuki K, Kohn LD, Saji M, Ringel MD. Regulation of FRTL-5 thyroid cell growth by phosphatidylinositol $(\mathrm{OH}) 3$ kinase-dependent Akt-mediated signaling Thyroid 2001;11:339-51.

11 Rodriguez-Viciana P, Warne PH, Dhand R, Vanhaesebroeck B, Gout I, Fry MJ, Waterfield MD, Downward J. Phosphatidylinositol-3-OH kinase as a direct target of Ras. Nature 1994;370:527-32.

12 Borrello MG, Pelicci G, Arighi E, De Filippis L, Greco A, Bongarzone I, Rizzetti M, Pelicci PG, Pierotti MA. The oncogenic versions of the Ret and Trk tyrosine kinases bind Shc and Grb2 adaptor proteins. Oncogene 1994;9:1661-8.

13 Kauffmann-Zeh A, Rodriguez-Viciana P, Ulrich E, Gilbert C, Coffer P, Downward J, Evan G. Suppression of c-Myc-induced apoptosis by Ras signalling through $\mathrm{PI}(3) \mathrm{K}$ and $\mathrm{PKB}$. Nature 1997;385:544-8.

14 Liu AX, Testa JR, Hamilton TC, Jove R, Nicosia SV, Cheng JQ. AKT2, a member of the protein kinase B family, is activated by growth factors, $\mathrm{v}-\mathrm{Ha}$ ras, and v-src through phosphatidylinositol 3-kinase in human ovarian epithelial cancer cells. Cancer Res 1998;58:2973-7.

15 Xing S, Furminger TL, Tong Q, Jhiang SM. Signal transduction pathways activated by RET oncoproteins in $\mathrm{PC} 12$ pheochromocytoma cells. J Biol Chem 1998;273:4909-14.

16 Califano D, Rizzo C, D’Alessio A, Colucci-D'Amato GL, Cali G, Bartoli PC, Santelli G, Vecchio G, de Franciscis V. Signaling through Ras is essential for ret oncogene-induced cell differentiation in $\mathrm{PCl} 2$ cells. J Biol Chem 2000;275: 19297-305

17 Barone MV, Sepe L, Melillo RM, Mineo A, Santelli G, Monaco C, Castellone MD, Tramontano D, Fusco A, Santoro M. RET/PTC1 oncogene signaling in PC Cl 3 thyroid cells requires the small GTP-binding protein Rho. Oncogene 2001;20:6973-82.

18 Besset V, Scott RP, Ibanez CF. Signaling complexes and protein-protein interactions involved in the activation of the Ras and phosphatidylinositol 3-kinase pathways by the c-Ret receptor tyrosine kinase. J Biol Chem 2000;275:39159-66.

19 Hennige AM, Lammers R, Arlt D, Hoppner W, Strack V, Niederfellner G, Seif FJ, Haring $H$, Kellerer M. Ret oncogene signal transduction via a IRS-2/PI 3-kinase/PKB and a SHC/Grb-2 dependent pathway: possible implication for transforming activity in NIH3T3 cells. Mol Cell Endocrinol 2000;167:69-76.

20 Segouffin-Cariou C, Billaud M. Transforming ability of MEN2A-RET requires activation of the phosphatidylinositol 3-kinase/AKT signaling pathway. J Biol Chem 2000;275:3568-76.

21 Monaco C, Visconti R, Barone MV, Pierantoni GM, Berlingieri MT, De Lorenzo C, Mineo A, Vecchio G, Fusco A, Santoro M. The RFG oligomerization domain mediates kinase activation and re-localization of the 
RET/PTC3 oncoprotein to the plasma membrane. Oncogene 2001;20:599-608

22 Melillo RM, Santoro M, Ong SH, Billaud M, Fusco A, Hadari YR, Schlessinger J, Lax I. Docking protein FRS2 links the protein tyrosine kinase RET and its oncogenic forms with the mitogen-activated protein kinase signaling cascade. Mol Cell Biol 2001;21:4177-87.

23 Staal SP. Molecular cloning of the akt oncogene and its human homologues AKT1 and AKT2: amplification of AKT1 in a primary human gastric adenocarcinoma. Proc Natl Acad Sci USA 1987:84:5034-7.

24 Masure S, Haefner B, Wesselink JJ, Hoefnagel E, Mortier E, Verhasselt $P$, Tuytelaars A, Gordon R, Richardson A. Molecular cloning, expression and characterization of the human serine/threonine kinase Akt-3. Eur J Biochem 1999;265:353-60.

25 Nakatani K, Sakave H, Thompson DA, Weigel RJ, Roth RA. Identification of a human $A k+3$ (protein kinase $B$ gamma) which contains the regulatory serine phosphorylation site. Biochem Biophys Res Commun 1999;257:906-10.

26 Alessi DR, Andjelkovic M, Caudwell B, Cron P, Morrice N, Cohen P, Hemmings BA. Mechanism of activation of protein kinase $B$ by insulin and IGF-1. EMBO J 1996;15:6541-51.

27 Kohn AD, Takeuchi F, Roth RA. Akt, a pleckstrin homology domain containing kinase, is activated primarily by phosphorylation. J Biol Chem 1996;271:21920-6

28 Aoki M, Batista O, Bellacosa A, Tsichlis P, Vogt PK. The AKT kinase: molecular determinants of oncogenicity. Proc Natl Acad Sci USA 1998;95:14950-5.

29 Cheng JQ, Ruggeri B, Klein WM, Sonoda G, Altomare DA, Watson DK, Testa JR. Amplification of AKT2 in human pancreatic cells and inhibition of AKT2 expression and tumorigenicity by antisense RNA. Proc Natl Acad Sci USA 1996:93:3636-41.

30 Ruggeri BA, Huang L, Wood M, Cheng JQ, Testa JR. Amplification and overexpression of the AKT2 oncogene in a subset of human pancreatic ductal adenocarcinomas. Mol Carcinog 1998;21:81-6.

31 Hill MM, Clark SF, Tucker DF, Birnbaum MJ, James DE, Macaulay SL. A role for protein kinase Bbeta /Akt2 in insulin-stimulated GLUT4 translocation in adipocytes. Mol Cell Biol 1999;19:7771-81.

32 Nakatani K, Thompson DA, Barthel A, Sakaue H, Liu W, Weigel RJ, Roth RA. Up-regulation of Akł3 in estrogen receptor-deficient breast cancers and androgen-independent prostate cancer lines. J Biol Chem 1999;274:21528-32

33 Kim YB, Peroni OD, Franke TF, Kahn BB. Divergent regulation of Aktl and $A k+2$ isoforms in insulin target tissues of obese Zucker rats. Diabetes 2000:49:847-56.

34 Tsai EM, Wang SC, Lee JN, Hung MC. Akt Activation by estrogen in estrogen receptor-negative breast cancer cells. Cancer Res 2001;61:8390-2.

35 Zinda MJ, Johnson MA, Paul JD, Horn C, Konicek BW, Lu ZH, Sandusky G, Thomas JE, Neubauer BL, Lai MT, Graff JR. AKT-1,-2, and-3 are expressed in both normal and tumor tissues of the lung, breast, prostate, and colon. Clin Cancer Res 2001;7:2475-9.

36 Sumitani S, Goya K, Testa JR, Kouhara H, Kasayama S. Akt1 and Akt2 differently regulate muscle creatine kinase and myogenin gene transcription in insulin-induced differentiation of $\mathrm{C} 2 \mathrm{C} 12$ myoblasts. Endocrinology 2002; 143:820-8.

37 Cho H, Mu J, Kim JK, Thorvaldsen JL, Chu Q, Crenshaw EB 3rd, Kaestner KH, Bartolomei MS, Shulman GI, Birnbaum MJ. Insulin resistance and a diabetes mellitus-like syndrome in mice lacking the protein kinase Ak+2 (PKB beta). Science $2001 ; 292: 1728-31$.

38 Chen WS, Xu PZ, Gottlob K, Chen ML, Sokol K, Shiyanova T, Roninson I, Weng W, Suzuki R, Tobe K, Kadowaki T, Hay N. Growth retardation and increased apoptosis in mice with homozygous disruption of the Aktl gene. Genes Dev 2001:15:2203-8.

39 Basso AD, Solit DB, Chiosis G, Giri B, Tsichlis P, Rosen N. Akt forms an intracellular complex with $\mathrm{Hsp} 90$ and $\mathrm{Cdc} 37$ and is destabilized by inhibitors of Hsp90 function. J Biol Chem 2002;277:39858-66.

40 Mitsuuchi Y, Johnson SW, Sonoda G, Tanno S, Golemis EA, Testa JR. Identification of a chromosome 3p14.3-21.1 gene, APPL, encoding an adaptor molecule that interacts with the oncoprotein-serine/threonine kinase AKT2. Oncogene 1999;18:4891-8

41 Koh H, Lee KH, Kim D, Kim S, Kim JW, Chung J. Inhibition of Akt and its antiapoptotic activities by fumor necrosis factor-induced protein kinase C-related kinase 2 (PRK2) cleavage. J Biol Chem 2000;275:34451-8.
42 Maira SM, Galetic I, Brazil DP, Kaech S, Ingley E, Thelen M, Hemmings BA Carboxyl-terminal modulator protein (CTMP), a negative regulator of PKB/Akt and v-Akt at the plasma membrane. Science $2001 ; 294: 374-80$.

43 Laine J, Kunstle G, Obata T, Sha M, Noguchi M. The protooncogene TCL1 is an Akt kinase coactivator. Mol Cell 2000:6:395-407.

44 Pekarsky Y, Koval A, Hallas C, Bichi R, Tresini M, Malstrom S, Russo G, Tsichlis $\mathrm{P}$, Croce CM. Tcll enhances Akt kinase activity and mediates its nuclear translocation. Proc Natl Acad Sci USA 2000;97:3028-3033.

45 French SW, Shen RR, Koh PJ, Malone CS, Mallick P, Teitell MA. A modeled hydrophobic domain on the TCL1 oncoprotein mediates association with AKT at the cytoplasmic membrane. Biochemistry 2002;41:6376-82.

46 Laine J, Kunstle G, Obata T, Noguchi M. Differential regulation of Akt kinase isoforms by the members of the TCL1 oncogene family. J Biol Chem 2002;277:3743-51.

47 Lawlor MA, Alessi DR. PKB/Akt: a key mediator of cell proliferation, survival and insulin responses? J Cell Sci 2001;114:2903-10.

48 Nicholson KM, Anderson NG. The protein kinase B/Akt signalling pathway in human malignancy. Cell Signal 2002;14:381-95.

49 Testa JR, Bellacosa A. AKT plays a central role in tumorigenesis. PNAS $2001 ; 98: 10983-5$.

50 Scheid MP, Woodgett JR. PKB/AKT: functional insights from genetic models. Nat Rev Mol Cell Biol $2001 ; 2: 760-8$

51 Meili R, Ellsworth $\mathrm{C}$, Lee S, Reddy TB, Ma H, Firtel RA. Chemoattractantmediated transient activation and membrane localization of Akt/PKB is required for efficient chemotaxis to CAMP in Dictyostelium PG. EMBO J 1999; 18:2092-105.

52 Servant G, Weiner OD, Herzmark P, Balla T, Sedat JW, Bourne HR. Polarization of chemoattractant receptor signaling during neutrophil chemotaxis. Science 2000;287:1037-40.

53 Park BK, Zeng X, Glazer RI. Aktl induces extracellular matrix invasion and matrix metalloproteinase-2 activity in mouse mammary epithelial cells. Cancer Res 2001;61:7647-53.

54 Tanno S, Tanno S, Mitsuuchi Y, Altomare DA, Xiao G-H, Testa JR. AKT Activation up-regulates insulin-like growth factor 1 receptor expression and promotes invasiveness of human pancreatic cancer cells. Cancer Res $2001 ; 6: 589-93$

55 Kim D, Kim S, Koh H, Yoon SO, Chung AS, Cho KS, Chung J. Akt/PKB promotes cancer cell invasion via increased motility and metalloproteinase production. FASEB J 2001;15:1953-62.

56 Higuchi M, Masuyama N, Fukui Y, Suzuki A, Gotoh Y. Akt mediates Rac/ Cdc42-regulated cell motility in growth factor-stimulated cells and in invasive PTEN knockout cells. Curr Biol 2001:11:1958-62.

57 Pérez-Tenorio G, Stål O. Activation of AKT/PKB in breast cancer predicts a worse outcome among endocrine treated patients. $\mathrm{Br} J$ Cancer 2002;86:540-5

58 Rodier G, Montagnoli A, Di Marcotullio L, Coulombe P, Draetta GF, Pagano M, Meloche S. p27 cytoplasmic localization is regulated by phosphorylation on Ser10 and is not a prerequisite for its proteolysis. EMBO J 2001;20:6672-82.

59 Liang J, Zubovitz J, Petrocelli T, Kotchetkov R, Connor MK, Han K, Lee JH, Ciarallo S, Catzavelos C, Beniston R, Franssen E, Slingerland JM. PKB/Ak phosphorylates p27, impairs nuclear import of p27 and opposes p27mediated G1 arrest. Nat Med 2002;8:1153-60

60 Shin I, Yakes FM, Rojo F, Shin NY, Bakin AV, Baselga J, Arteaga CL. PKB/Akt mediates cell-cycle progression by phosphorylation of $\mathrm{p} 27^{\mathrm{Kip}}$ at threonine 157 and modulation of its cellular localization. Nat Med 2002:8:1 145-52.

61 Viglietto G, Motti ML, Bruni P, Melillo RM, D'Alessio A, Califano D, Vinci F, Chiappetta G, Tsichlis P, Bellacosa A, Fusco A, Santoro M. Cytoplasmic relocalization and inhibition of the cyclin-dependent kinase inhibitor $\mathrm{p} 27^{\mathrm{Kip} 1}$ by PKB/Akt-mediated phosphorylation in breast cancer. Nat Med 2002;8:1136-44.

62 Khoo MLC, Beasley NJP, Ezzat S, Freeman JL, Asa SL. Overexpression of cyclin D1 and underexpression of p27 predict lymph node metastases in papillary thyroid carcinoma. J Clin Endocrinol Metab 2002;87:1814-18.

63 De Vita G, Melillo RM, Carlomagno F, Visconti R, Castellone MD, Bellacosa A, Billaud M, Fusco A, Tsichlis PN, Santoro M. Tyrosine 1062 of RET-MEN2A mediates activation of Akt (protein kinase B) and mitogen-activated protein kinase pathways leading to $\mathrm{PC} 12$ cell survival. Cancer Res 2000;60:3727-31 